\title{
Preliminary Study of Emissions Regulation Effects on Future Commercial Aircraft Designs
}

\author{
Fairuz I. Romli and Mohd Syahidie Kamaruddin
}

\begin{abstract}
Conventional aircraft designs have long been highly successful for commercial passengers transport markets. In recent years, there are researches carried out to explore a few revolutionary concepts such as the blended wing body. With expected stricter environmental regulations to be imposed by the aviation regulatory bodies for future flight operations, questions arise on the relevancy of conventional aircraft designs to remain competitive in years to come and on whether the search for new revolutionary aircraft designs has become necessary. This study aims to assess the situation by analyzing the projected emission performance of conventional aircraft designs through changes of their parameters. Overall, the results indicate that conventional aircraft designs face a tough chance to remain competitive when the proposed regulation takes place and a more aerodynamically efficient design is necessary.
\end{abstract}

Index Terms-Aircraft design, emissions, fuel efficiency.

\section{INTRODUCTION}

The increase in global air traffic, which is expected to rise by a factor of 5 or 6 within 60 years from the recorded volume in year 1990 [1], also means a significant rise in total aviation emissions. Coupled that with a higher potential improvement in other sectors, contribution from air transportation industry is predicted to nominally increase up to $15 \%$ by year 2050 [2]. In response to this, policy makers have taken serious efforts to govern and regulate the future aircraft emission. For instance, European Union has started to regulate all operating airlines to hold emission permits that commensurate the $\mathrm{CO}_{2}$ pollution generated by their fleet [3]. Moreover, the International Civil Aviation Organization (ICAO) set a goal among the airlines to improve their fuel efficiency by an average of $1.5 \%$ per year between 2010 and 2020 that amounts to estimated 2.2 billion tones in $\mathrm{CO}_{2}$ savings [4]. Major actors within the European aviation markets also have set for new aircraft by year 2020 to have $50 \%$ less $\mathrm{CO}_{2}$ and $80 \%$ less $\mathrm{NO}_{\mathrm{x}}$ emissions [5]. Based on these, it can be anticipated that future aviation environmental regulations will be much stricter than the current ones.

Aircraft emissions during operation are mostly contributed to the products of its fuel combustion, which are comprised of mainly carbon dioxide $\left(\mathrm{CO}_{2}\right)$ and water vapor. Other emission products such as sulphur dioxide, nitrogenous oxides, carbon monoxide, soot and hydrocarbons are in comparatively much smaller quantities. One of the proposed

Manuscript received December 20, 2012; revised February 15, 2013.

Fairuz I. Romli and M. Syahidie Kamaruddin are with the Aerospace Engineering Department, Universiti Putra Malaysia, Selangor, Malaysia (e-mail: firomli@eng.upm.edu.my). key levers to reduce these harmful aircraft emissions is to improve the level of fuel efficiency for the flight operation. With this notion in mind, this research paper aims to analyze the projected performance of conventional aircraft designs in satisfying the future stricter regulation through increased operational fuel efficiency.

\section{AIRCRAFT FUEL EFFICIENCY}

In this paper, the fuel efficiency is measured by the amount of required fuel burned over a flight distance. Raymer [6] has suggested that the aircraft takeoff weight, $W_{0}$ can be related to the required fuel weight, $W_{f}$ through the following equations (1) and (2).

$$
W_{f}=1.06\left(1-\frac{W_{x}}{W_{0}}\right) W_{0}
$$

$$
\frac{W_{x}}{W_{0}}=\left[\begin{array}{l}
\text { Takeoff Weight Fraction } \times \text { Climb Weight Fraction } \\
\times \text { Cruise Weight Fraction } \times \text { Loiter Weight Fraction } \\
\times \text { Landing Weight Fraction }
\end{array}\right]
$$

As can be implied from (2), the commercial flight mission can be broken into a few major stages and the cruise segment is the longest part. This is also the phase where the amount of required fuel burned is the largest. For a given mission cruise range, the relationship between the amount of required fuel (i.e. in terms of cruise weight fraction) and the mission cruise range could be explored through the Breguet range equation as given in (3) where $R=$ range, $V_{\infty}=$ velocity, TSFC $=$ thrust specific fuel consumption and $(\mathrm{L} / \mathrm{D})=$ lift-to-drag ratio [6].

$$
R=\frac{V_{\infty}}{T S F C} \frac{L}{D} \ln [\text { Cruise Weight Fraction }]
$$

From (3), there are two parameters of aircraft design that can have significant influence on the required amount of fuel for a given cruise condition. They are the thrust specific fuel consumption (TSFC) and the lift-to-drag ratio (L/D). Over the years, improvement of TSFC has been achieved through new technologies developed for the aircraft propulsion subsystem (i.e. engine). Among the explored research areas to improve TSFC include ultra-high bypass turbofan and alternative fuel. On the other end, L/D parameter is linked to the aerodynamic characteristics of the aircraft design. An example research to improve $\mathrm{L} / \mathrm{D}$ is by changing the aircraft design to increase the laminar flow over the aircraft surfaces hence increasing the overall lift and reducing the drag. This leads to several new revolutionary concepts like the blended-wing-body (BWB), which theoretically will improve $\mathrm{L} / \mathrm{D}$ over the conventional aircraft designs. 
The historical trend of TSFC advancement for different classes of conventional aircraft designs is shown in Fig. 1. It can be observed from the Fig that the TSFC is getting lower throughout the years, which is a good development to reduce the fuel amount required for flight operation.

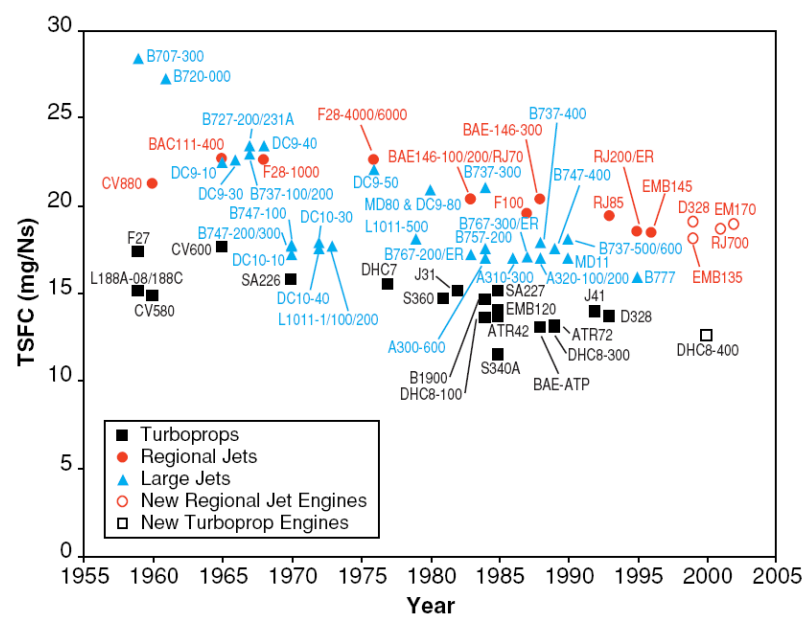

Fig. 1. Historical trend of TSFC [7]

Meanwhile, the improvements achieved for L/D through the enhancement of conventional aircraft designs such as from use of lighter composite materials and/or better aerodynamics design can be observed in following Fig. 2 . Similar to TSFC, the improvement in L/D is encouraging as it appears to be on an increasing trend throughout the years. It should be noted that a higher L/D can help save fuel, hence increasing the fuel efficiency.

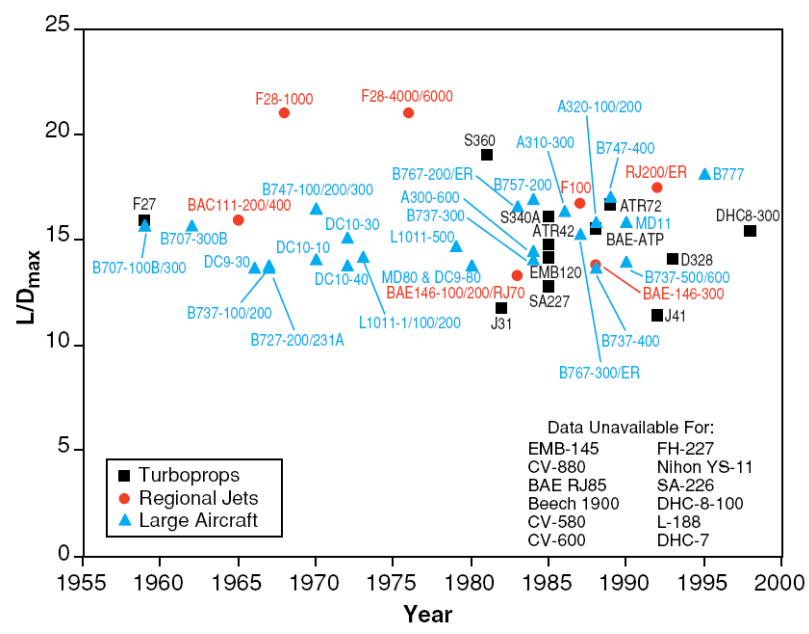

Fig. 2. Historical trend of maximum lift-to-drag ratio [7]

\section{SimUlation ANALYSIS}

It is observed that many of the aircraft manufacturers still maintain a conventional design for their aircraft products. To get by the future operational requirements, they heavily rely on new technologies that have been developed to improve the aircraft subsystems. On contrary, many revolutionary designs of aircraft have already been adopted in other aviation fields such as the military and unmanned aerial vehicle (UAV). It is nonetheless an understandably difficult decision to introduce new revolutionary designs for commercial transport aircraft due to the high level of operational and financial risks that are coupled with it. Airlines are keener to have the high reliability of matured technologies and designs rather than to cope with extra risks of new revolutionary ones. However, questions are raised on whether the reliance on subsystem improvements is enough to guarantee that the conventional aircraft designs are still operable when a stricter environmental regulation comes to effect. Such concern arises after realizing that many of the technological options to reduce aircraft emissions are largely unproven or still several years under research or development [8]. To address this question, a simulation study was done on the projected fuel efficiency improvement that is expected of the conventional aircraft designs from the improvement of the TSFC and L/D parameters.

The analysis in this study was referenced to future emission reduction goals envisioned by NASA, which was set based on the emissions level that existed in 1997. Of particular interest here is the expected $50 \%$ reduction of $\mathrm{CO}_{2}$ by year 2022 [9]. It was simply taken that to satisfy the $50 \%$ reduction of $\mathrm{CO}_{2}$, the amount of fuel burned also has to be reduced by $50 \%$. From previous Fig. 1 and Fig. 2, an empirical linear regression fit was derived to estimate the improvements achieved on TSFC and $L / D$, respectively, throughout the years. An assumption here, which seems appropriate by looking at the trend in Fig. 1 and Fig. 2, was that the improvement follows a linear trend line. The relationships were given by (4) and (5) for the large jets aircraft category.

$$
\begin{gathered}
T S F C=-0.264(\text { Year }-1962)+22.89 \quad[\mathrm{in} \mathrm{mg} / \mathrm{Ns}] \\
L / D=0.156(\text { Year }-1966)+13.11
\end{gathered}
$$

Using (4) and (5), the reference emissions level in 1997 for NASA goals could be calculated. This corresponds to values of TSFC $=13.65 \mathrm{mg} / \mathrm{Ns}$ and maximum $L / D=18$. Theoretical mission profile used for the analysis was roughly estimated from that of Boeing 737-700 aircraft, which was introduced into the market in 1998. In this reference, the mission cruise range was set to $5650 \mathrm{~km}$ and the maximum cruise speed was at Mach 0.78 or $823 \mathrm{~km} / \mathrm{h}$. The procedure for estimating the takeoff gross weight was outlined in [6] and parameters' setting was validated by comparing the calculated takeoff weight from the procedure with the published weight for the Boeing B737-700 aircraft. As presented in Table I, the result was acceptable with only a very small error of $0.06 \%$. Subsequently, the calculated fuel weight to be used as the 1997 standard for the analysis was estimated as $16719.14 \mathrm{~kg}$. This means that by 2022 , if $50 \%$ reduction in required fuel weight was sought, the total fuel weight should be reduced down to just $8359.57 \mathrm{~kg}$.

TABLE I: \% ERROR IN TAKEOFF GROSS WEIGHT CALCULATION

\begin{tabular}{ccc}
\hline $\begin{array}{c}\text { Published Takeoff Gross } \\
\text { Weight of B737-700 }\end{array}$ & $\begin{array}{c}\text { Calculated Takeoff } \\
\text { Gross Weight }\end{array}$ & \% Error \\
\hline $65500.00 \mathrm{~kg}$ & $65539.56 \mathrm{~kg}$ & 0.06 \\
\hline
\end{tabular}

To simulate the projected improvements that are expected for conventional aircraft designs in large aircraft category in order to satisfy the NASA reduction goals, the values of both TSFC and L/D were varied. Because there are uncertainties 
on whether the projected improvement from the empirical equations (4) and (5) could be truly achieved, a stochastic analysis was more reasonable rather than a deterministic approach. Based on this notion, a Monte Carlo simulation was run to seek the required range of TSFC and $L / D$ values to reduce the fuel weight to the $50 \%$ level. For a conservative analysis, the distribution for the values $L / D$ was set as uniform with the lower limit was its standard 1997 value as previously established. On the other hand, the standard 1997 value of TSFC became the upper limit of its uniform sampling distribution. To facilitate the computation, a MATLAB program was developed to run for 100,000 cases. The steps taken during the analysis procedure are summarized in process block diagram as shown in Fig. 3.

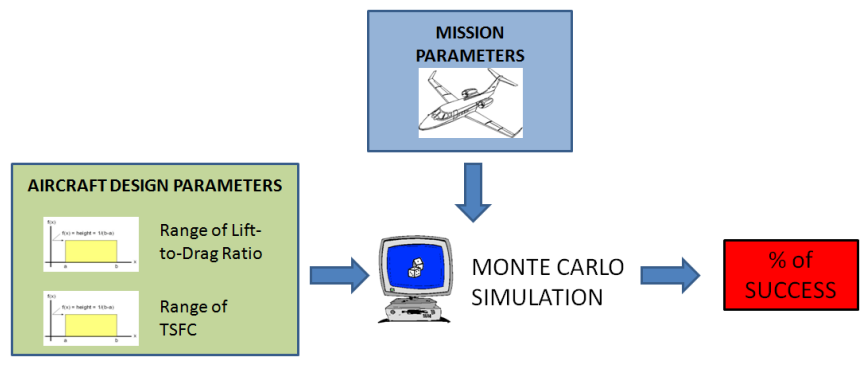

Fig. 3. Summarized block diagram of the analysis process [10]

\section{RESUlts AND DiscussiOnS}

Based on (4) and (5), the projected improvements of TSFC and $L / D$ values by 2022 are $7.05 \mathrm{mg} / \mathrm{Ns}$ and 22, respectively. These will become the lower limit and the upper limit of the sampling distribution for TSFC and $L / D$, respectively. First of all, the study analyzes whether conventional aircraft designs can really achieve the target reduction goal with the expected improvements. With the specified range setting of TSFC and $L / D$ values as shown is Table II, the simulation procedure was run three times and the results are presented in Fig. 4.

TABLE II: PARAMETER SETTINGS FOR MONTE CARLO SimUlation

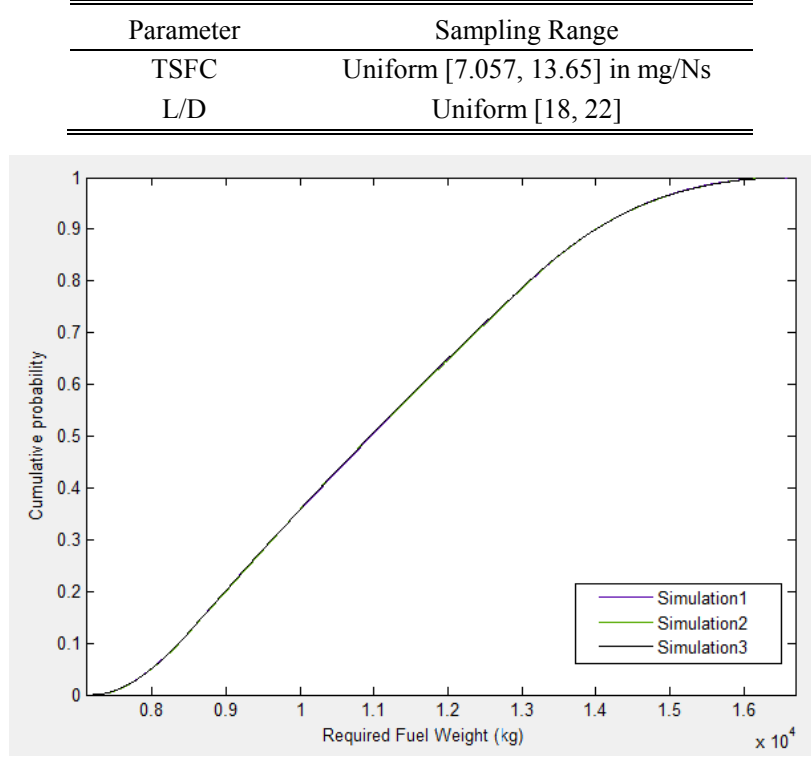

Fig. 4. Resultant CDF plot

It should be noted that each simulation run was executed with a different initial guess estimate for the takeoff gross weight calculation procedure. Regardless of this, it can be seen that all three resultant cumulative density functions as presented in Fig. 4 are extremely consistent with each other. This condition highlights the stability of the simulation program and the high reliability of its results. As can be observed from the plot, the estimated probability of success that the conventional aircraft designs can achieve the target reduction goal is approximately just $10 \%$. This is perceived to imply that the current rate of the advancements in aircraft subsystem technologies to improve on TSFC and $L / D$ might not be made fast enough to ensure that conventional aircraft designs can still remain competitive under the expected new regulation.

Further investigation is done to find the required value of TSFC to enable success for the conventional designs. This is done while keeping the range of $L / D$ values similar to before. It is found that, even if the TSFC value is decreased until zero, the probability of success for the conventional aircraft design is just approximately $55.5 \%$ as shown in Fig. 5. Hence, it can be concluded that the improvement on TSFC alone cannot be relied upon to cope with future stricter environmental rules. On the other hand, the simulation results for the variation of $L / D$ values while keeping the same range of TSFC values are shown in Fig. 6. It has been found that, even when the upper limit of $L / D$ is increased way up to 60 , the percent of success to satisfy the target emission reduction goals by 2022 is still just about $80 \%$. Combining these two extreme ranges of the TSFC and $L / D$ sampling, the simulation results are shown in Fig. 7. It can be seen that the percentage of success has now increased to $91 \%$. Nonetheless, in reality, it would be rather impossible to get such TSFC and $L / D$ values for conventional aircraft designs with the current technological researches.

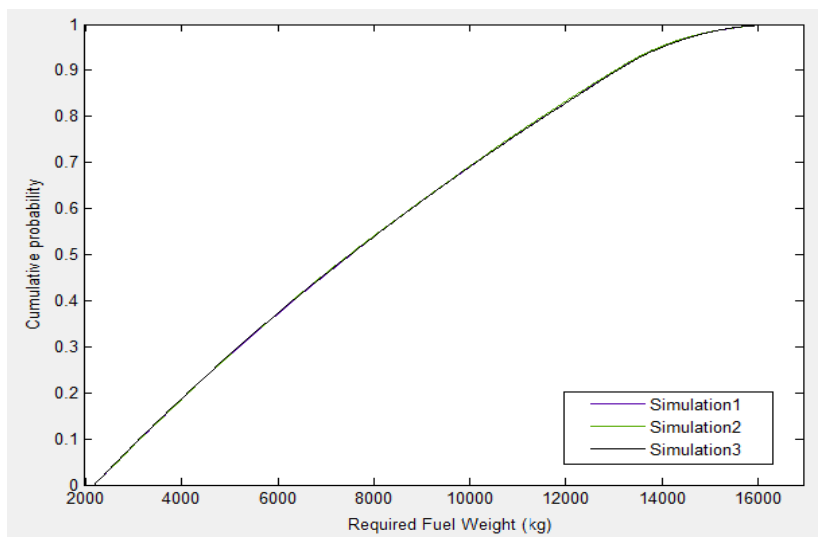

Fig. 5. Resultant CDF plot with $T S F C=[0,0.48]$

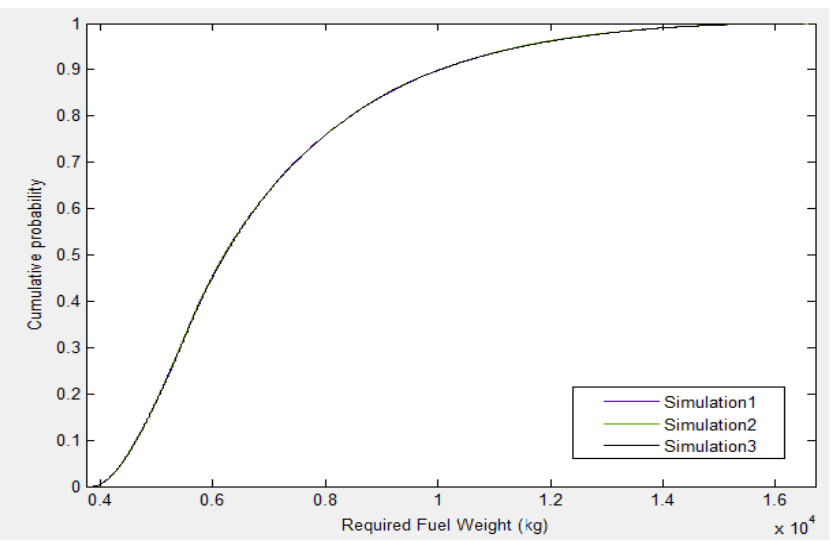

Fig. 6. Resultant CDF plot with $L / D=[18,60]$ 


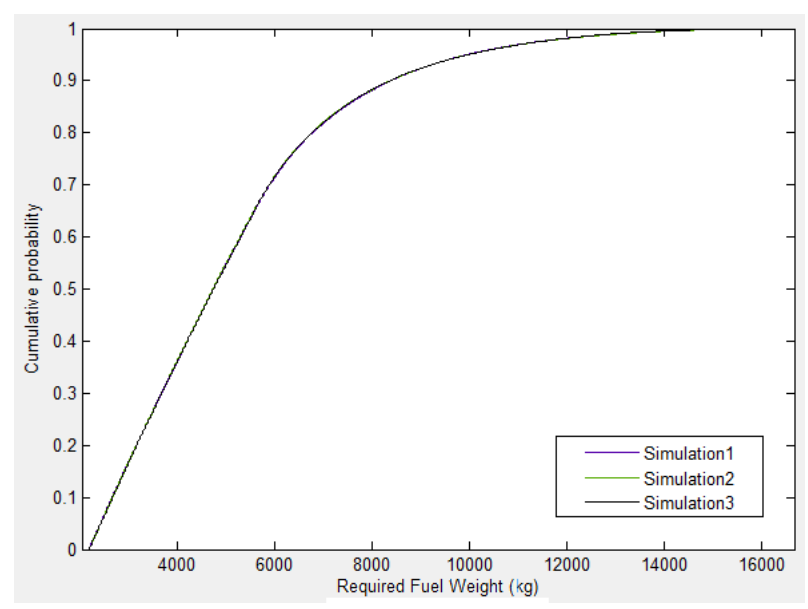

Fig. 7. Resultant CDF plot with $L / D=[18,60]$ and $T S F C=[0,0.48]$

\section{CONCLUSIONS}

The results from the simulation study give an insight to the big challenges that conventional aircraft designs might face in coping with the expected stricter environmental regulation. Even though the analysis done here is very conservative and the NASA goals used as the measure here are rather extreme, the results nonetheless highlight the problem with relying on subsystems advancement to ensure the aircraft designs remain competitively operational in future. Hence this creates a need to explore the other revolutionary aircraft designs such as the blended wing body for commercial transport use, whereby its better aerodynamic features might help improve the chances to satisfy the emissions reduction goals.

\section{REFERENCES}

[1] D. P. Garber, P. Minnis, and P. K. Costulis, "A Commercial Flight Track Database for Upper Tropospheric Aircraft Emission Studies over the USA and Southern Canada," Meteorologische Zeitschrift, vol. 14, no. 4, pp. 445-452, 2005.
[2] S. Sgouridis, P. A. Bonnefoy, and R. J. Hansman, "Air Transportation in a Carbon Constrained World: Lo ng-term Dynamics of Policies and Strategies for Mitigating the Carbon Footprint of Commercial Aviation," Transportation Research Part A, vol. 45, pp. 1077-1091, 2011.

[3] J. K. Brueckner and A. Zhang, "Airline Emission Charges: Effects on Airfares, Service Quality and Aircraft Design," Transportation Research Part B, vol. 44, pp. 960-971, 2010.

[4] Air Transport Action Group, The Right Flightpath to Reduce Aviation Emissions, UNFCCC Climate Talks, 2010.

[5] P. Arguelles et al., European Aeronautics: A Vision for 2020, Report of the Group of Personalities, 2001.

[6] D. P. Raymer, Aircraft Design: A Conceptual Approach, Washington, D. C.: American Institute of Aeronautics and Astronautics, Inc. 1992.

[7] R. Babikian, "The Historical Fuel Efficiency Characteristics of Regional Aircraft from Technological, Operational and Cost Perspectives," Department of Aeronautics and Astronautics, Massachusetts Institute of Technology, 2001.

[8] B. Block, "Aviation Industry Outlines Ambitious Climate Goals," Worldwatch Institute, 2011.

[9] T. J. Wickenheiser et al., "Emissionless Aircraft: Requirements and Challenges," AIAA/ICAS International Air and Space Symposium and Exposition: The Next 100 Y, Dayton, USA, 2003.

[10] F. I. Romli and M. S. Kamaruddin, "Emissions Performance Study for Conventional Aircraft Designs," Applied Mechanics and Materials, vol. 225, pp. 385-390, 2012.

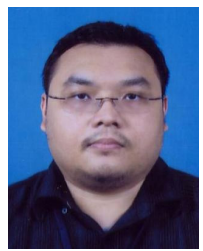

Fairuz I. Romli received his Ph.D. in Aerospace Engineering from Georgia Institute of Technology, USA in 2009. He currently works as a Senior Lecturer in the Department of Aerospace Engineering, Universiti Putra Malaysia, Malaysia. His research interests include systems design methodologies and tools, optimization studies and also air traffic management.

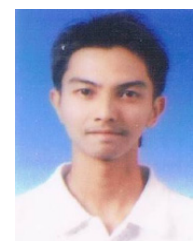

Mohd Syahidie Kamaruddin received his Bachelor degree in Aerospace Engineering from Universiti Putra Malaysia, Malaysia in 2012. 